\title{
EVALUATING THE EFFECT OF CONSERVATION MOTIVATIONS ON RESIDENTIAL WATER DEMAND
}

\author{
Alexander Maas $^{\mathrm{a}^{*}}$, Christopher Goemans ${ }^{\mathrm{b}}$, Dale Manning ${ }^{\mathrm{b}}$, Stephan Kroll ${ }^{\mathrm{b}}$, Mazdak Arabi $^{\mathrm{a}}$ \\ ${ }^{a}$ Department of Civil and Environmental Engineering. Colorado State University. 400 Isotope Drive. Fort Collins \\ CO 80521 \\ ${ }^{\mathrm{b}}$ Department of Agricultural and Resource Economics. Colorado State University. 1200 Center Ave. Mall. Fort \\ Collins CO 80523 \\ * Corresponding Author: email: alexander.s.maas@gmail.com
}




\title{
EVALUATING THE EFFECT OF CONSERVATION MOTIVATIONS ON RESIDENTIAL WATER DEMAND
}

\begin{abstract}
Utilities and water suppliers in the southwestern United States have used education and conservation programs over the past two decades in an attempt to ameliorate the pressures of increasing water scarcity. This paper builds on a long history of water demand and environmental psychology literature and attempts to answer a simple question: do households primarily motivated by environmental and social (E\&S) considerations consume water differently than households motivated primarily by cost and convenience $(\mathrm{C} \& \mathrm{C})$ ? We find that $E \& S$ consumers use less water than $C \& C$ consumers on average. We also find that there is no statistical difference between $\mathrm{E} \& \mathrm{~S}$ and $\mathrm{C} \& \mathrm{C}$ consumers in their consumption responses to changing prices, temperature, and precipitation. This implies that targeting future conservation efforts to self-reported consumer groups may not improve policy effectiveness.
\end{abstract}

\section{Keywords}

Residential Water Demand; Water Use Motivations; Water Management; Conservation Attitudes 


\section{Introduction}

As natural resources such as water become increasingly scarce, managers often seek policies to reduce demand (Gleick 2000). In urban water systems, individual household characteristics strongly influence the effectiveness of demand-side management strategies (DSM) as well as the additional demands induced by hot and dry weather events (Kenney et al. 2008; Nieswiadomy 1992; Schleich and Hillenbrand 2009; Billings and Day 1989). Yet, little is known about the relationship between household conservation motivations and realized consumption. Understanding how customer motivations translate to consumption responses will help municipal water providers anticipate changes in household consumption patterns and effectively plan supply and distribution systems. Recent studies have attempted to better understand household water consumption decisions either through the creation of household classes or by including household characteristics directly into the demand equations, but these studies have traditionally focused on the effect of observable household characteristics such as house size. Few studies of US water consumers have used stated preference methods to evaluate the effect of underlying motivations on revealed residential water use and conservation.

Utilities and water suppliers in the southwestern United States have introduced a number of education and conservation programs over the past two decades in an attempt to address increasing water scarcity. While programs differ from city to city, they are generally designed for the representative customer in a service region. However, Willis et al. (2011) opine that "[d]etermining motives for saving water are key when designing educational urban water saving strategies; hence at the outset, an understanding of consumption and attitudes towards water is vital." Moreover, convenience, cost, social pressure, and environmental attitudes have all been shown to be motivating factors in conservation (Olmstead et al. 2007; Olmstead and Stavins 2009; Arbués et al. 2016; Trumbo and O'Keefe 2001). Thus, understanding the relative effects of each motivation on water consumption has implications for designing programs and policies. This paper investigates the relationship between underlying motivations of conservation and water consumption decisions by using household level utility data and telephone surveys.

Economic theory and previous research suggest that individual consumers will decrease water use when the price of water increases (Espey et al. 1997; Dalhuisen et al. 2003). It also suggests that if precipitation and temperature are intermediary goods in the creation of a household good or service - a green lawn or garden for example - municipal water and precipitation are likely substitutes such that increased rain should decrease municipal water consumption. Indeed, these results have been found in numerous settings (Arbués et al. 2003; Worthington and Hoffman 2008). Standard economic theory, however, does little to help us understand how stated environmental and cost motivations interact with weather and price shocks with respect to consumption behavior. Thus, we propose and test a series of hypotheses to empirically elucidate how consumers' stated preferences influence responses to price and the weather.

\section{Hypothesis 1}

Households primarily motivated by environmental and social (E\&S) considerations consume less total water than consumers primarily motivated by cost and convenience $(\mathrm{C} \& \mathrm{C})$. 


\section{Hypothesis 2}

$\mathrm{E} \& \mathrm{~S}$ consumers respond less to changes in price than $\mathrm{C} \& \mathrm{C}$ consumers. Ceteris paribus, we hypothesize customers concerned with cost will have more elastic demand with respect to price.

\section{Hypothesis 3}

E\&S consumers and $\mathrm{C} \& \mathrm{C}$ consumers will respond identically to changes in monthly precipitation and temperature.

These questions are of particular interest because they provide direction for water suppliers' future education and conservation programs. Moreover, they must be answered empirically because theory does little to guide our hypotheses. Our results reveal that E\&S consumers use less water on average, but both consumer groups respond identically to variation in price and weather. This result has important implications for water and other resource managers because it suggests that heterogeneity in consumer motivations may not lead to different responses to weather events or conservation policies.

The remainder of this paper is comprised of four sections: in the next section we briefly summarize the existing water demand and environmental psychology literature. Section three outlines our methodology and data, section four presents our results, and section five concludes.

\section{Background}

A severe drought in 2002 and 2003 alerted the Colorado Water Conservation Board (CWCB) to the importance of promoting water conservation and efficiency throughout the state Colorado. Utility providers have since adopted a suite of price and non-price DSM strategies, including education programs, sprinkler audits, rebates, and increasing block rate (IBR) pricing structures. IBR's are designed to discourage use by increasing the marginal price of water as individual household consumption enters higher tiers and is often the most cost effective tool with which to manage demand (Olmstead and Stavins 2009; Arbués et al. 2003). However, the effectiveness of price as a conservation tool largely depends on the ability and desire of customers to cut back on their water use. Naturally, we anticipate that customers concerned primarily with cost may respond differently to price increases than those concerned with environmental or social issues. Moreover, the effectiveness of each DSM strategy may depend on the motivations and characteristics of water customers, but little is known about the effect of conservation motives on consumption choices.

Considerable research has been dedicated to the relationship between household characteristics and water consumption behavior; we return to this area for two reasons. First, only a few studies focus on the effect of underlying attitudes and beliefs on water consumption, the majority of which are specific to Australia. Randolph and Troy (2008) find that attitudes and culture significantly affect water use, and for this reason estimates in one city may not be externally valid for another. Accordingly, previous qualitative results may or may not be replicable in new geographic areas (Willis et al. 2013). As such, our analysis is similar to investigation of water use in Eastern Australia, but applied to a representative city in the southwestern United States. The second goal of this study is to add another data point to the debate over environmental 
attitudes and actions, which has substantial implications for how to efficiently incentivize resource conservation.

Research has linked environmental attitudes and beliefs to a host of environmental conscientious actions such as recycling, composting, efficient appliance installation, and conservation (Cialdini et al. 1990; Taylor and Todd 1997; Millock and Nauges 2010). In the specific context of water, a number of underlying motivations have been linked to lower consumption levels, including reducing costs (Olmstead and Stavins 2009; Arbués et al. 2003), normative social pressure (Trumbo and O'Keefe 2001; Corral-Verdugo and Frías-Armenta 2006), responding to possible punishment (Agras, Jacob, and Lebedeck 1980), and pro-environmental attitudes (CorralVerdugo et al. 2003). While the majority of findings suggest that environmental attitudes are linked to pro-environmental actions, these results are far from unanimous. A number of studies with inconsistent results linking attitudes to actions exist in environmental psychology literature (Gregory and Leo 2003; Tuan 1968). In many of these studies, environmental attitudes have been shown to insufficiently explain pro-environmental behavior (Kollmuss and Agyeman 2002; Poortinga et al. 2004).

A number of theories have been proposed to explain the possible discrepancies between attitude and action, with the Minimum Cost Theory garnering the most attention and support. Diekmann and Preisendörfer (1998) suggest that environmetnal conciousness will translate into behavior only when the monetary and/or non-monetary cost is sufficiently low. Thus, understanding how customers' motivations around cost and convenience lead to consumption and conservation decisions is a necessary step in creating effective conservation policies. This paradigm is particularly relevent for water suppliers who sponsor education and conservation programs, and suggests that convenience, along with environmental motivations, may be a strong driver in encouraging conservation.

Educational campaigns have been a common practice for most utilities, and evidence suggests that they are an effective conservation tool (Michelsen et al. 1999; Nieswiadomy 1992). However, it is difficult to determine if education programs simply provide knowledge-a prerequisite in changing behavior (Hungerford and Volk 1990)—which allows people to make more efficient decisions, or if education campaigns engender a sense of environmental stewardship which in turn increases the personal "value" of conservation. Simply put, it is unclear if education programs work because they reduce cost and increase convenience, or if they work because people feel good about conserving. Here, we begin to investigate this difference by measuring if the consumption decisions of households who claim to be motivated by cost and convenience differ from those motivated by social and environmental concerns.

Individuals motivated by environmental and social concerns are of particular interest because there is evidence that education campaigns focused on simply fostering environmental education can lead to long-term pro-environmental attitudes (Ballantyne and Packer 2005; Farmer et al. 2007). If E\&S motivated consumers use less (or respond differently) than their C\&C motivated counterparts, then education programs designed to shift attitudes may be an effective way to reduce water consumption. Indeed, there is some evidence that environmental education campaigns reduce consumption for this reason (Zsóka et al. 2013). 
Lastly, research suggests that stated primary motives, "such as altruistic and social values, are often covered up by the more immediate, selective motives, which evolve around one's own needs (e.g. being comfortable, saving money and time)" (Kollmuss and Agyeman 2002). Thus, even if households are environmentally and socially motivated, these attitudes may not translate into actions if significant barriers to conservation exist. Accordingly, the influence of cost, convenience, social and environmental motivations should be of great interest to policy makers attempting to design effective conservation programs.

\section{Methods}

To test whether individuals motivated by social and environmental considerations consume water differently than those motivated by cost and convenience, we need a robust indicator on which households are motivated by each factor. Combining motivations surveys with observable household characteristics found to influence water consumption and utility billing data allows us to investigate the relationship of motivations on consumption with proper control variables and test each of our hypotheses of interest.

Motivations data was collected using a household telephone survey conducted in a representative city in Colorado. In 2014 the city used a consulting service to author a customer segmentation study. While these questions were not designed to specifically answer our research questions, there are a number of questions embedded in the survey that elicit customer attitudes and beliefs. We therefore match survey responses to specific household billing data (for the years 20092014) in order to evaluate the relationship between stated motivations and observed consumption behavior. This data also allows us to identify how heterogeneous motivations affect water consumption responses to price and weather.

We focused on a subset of questions in the survey that directly elicit participant motivations for conservation. Survey respondents were asked to rate their effort in reducing water consumption for everyday activities on a scale from 0 (never try) to 9 (always try). Participants also indicated if their interest in reducing consumption was attributable to any of the following considerations: impact to the environment, impact on the community, cost to the household, and comfort and convenience. These questions were also answered on a scale from 0 (completely disagree) to 9 (completely agree). Although our analysis is focused on water consumption, the questions used in the survey asked about motivations for conservation for both water and electricity. We reasonably assume that the conservation motivation for water are equivalent to the motivations to conserve both water and electricity. The specific questions used in our analysis are as follows:

1) Please rate your level of effort to reduce or minimize the amount of water and electricity that you use.

2) When considering whether to use water or electricity, I consider the environmental impact that my household's water and electricity use will have on the community.

3) When considering whether to use water or electricity, I consider the economic impact that my household's water and electric use will have on the community.

4) When considering whether to use water or electricity, I consider how much it will cost my household to use those services. 
5) When considering whether to use water or electricity, I consider the comfort and convenience of those in my household.

\section{Customer Segmentation}

Households were classified as E\&S motivated if the sum of questions two and three was greater than the sum of questions four and five. If the opposite was true, households were labeled as $\mathrm{C} \& \mathrm{C}$ motivated. Households where the sums were equal across questions are excluded from the analysis since their primary stated motivation cannot be identified. Note that this classification does not mean that E\&S households do not consider cost or convenience; it only means that they are motivated to a greater extent by environmental and social concerns. The inverse is true for $\mathrm{C} \& \mathrm{C}$ consumers. To ensure robustness, different methods of grouping were considered and reported in the Appendix (A3); results from these regressions are qualitatively similar to those presented in the body of the paper.

The decision to divide customers into groups classified as $\mathrm{E} \& \mathrm{~S}$ and $\mathrm{C} \& \mathrm{C}$ was done for two reasons, and supported with a number of clustering tests presented in the results section. First, it is important to note that this division was decided by the researchers a priori to answer a specific question about socially and environmentally motivated individuals compared to cost and convenience motivations. Accordingly, we are not initially making claims about the similarity or dissimilarity of these customers on any metric except how they answer the above survey questions. To test specific hypotheses, we grouped environmentally and socially conscious customers into one group and cost and convenience conscious customers into another. However, it is worth evaluating this grouping decisions to see if such aggregation is justified. We investigate our grouping choice using a correlation matrix and Principal Component Analysis (PCA), as well as test for differences across groups using $t$ and chi-squared tests.

\section{Hypothesis Testing and Model Choice}

For proper hypothesis testing and to ensure robustness, we estimate two regression models and a series of t-tests. To address hypothesis 1 , we first use a t-test across consumer preference types to determine if unconditional water use is significantly different across E\&S and C\&C customers. Next, we use Model 1 (described below) where a dummy variable for E\&S customer type is included and the associated coefficient is tested for significance. While Model 1 provides a conditional mean that may isolate the effects of motivations from other household characteristics, it may also suffer from endogeneity. Thus, to test hypotheses 2 and 3 we use Model 2, which controls for unobserved, time-invariant household characteristics.

Hypothesis 2 and 3 refer to household consumption responses to external shocks, such that fixed effect (FE) models allow us to examine the coefficients of interest and average out any unobserved household specific characteristics that may cause biasness in the estimation. Using the regression specification from Model 2, we test the interaction coefficients for significance to determine if the marginal responses to weather and price differ across customer types. 
Attempting to identify causal relationships between household characteristics and water demand has been historically difficult. For example, Arbues et al. (2016) attempt to identify household factors that influence water saving behaviors. While such questions have numerous relevant applications for city planning and resource management, these analyses often lack a clear strategy for identifying causal impacts. Identification and endogeneity concerns arise from a number of sources that have been identified in the literature, where the chief issues are omitted variable bias and simultaneity (i.e., reverse causation).

The simultaneity concern arises because - by definition - price is a function of water use under increasing block rate price structures. Under such pricing, reverse causality is assured. Fortunately, this concern is solved indirectly by addressing another issue typically associated with estimating residential water demand, the lack of an immediate price signal. Consumers do not generally have real-time price information when making water consumption decision. Thus, researchers have largely agreed that the price signal to which households respond is that of last month's bill (Espey et al. 1997). Using last month's bill solves the simultaneity problem, but it is still possible that the price on last month's bill is correlated to the error term of this month's demand (for example, a broken pipe last month may affect water use decisions this month). Accordingly, we perform a Hausman test and find no evidence of endogeneity in the price variable.

The more serious concern is the possibility of unobserved variable bias or spurious correlations with variables omitted from the model. The crux of the issue is the possible correlation between explanatory variables and error due to unobserved or confounding variables, although the richness of our data and overall fit of our model is encouraging. For instance, three variables that are often unobserved and possibly correlated to explanatory variables in previous studies are conservation attitudes, environmental attitudes, and the area of irrigated turf. We have information on all three typically unobserved variables. Including these factors reduces, but does not eliminate concerns related to biased estimates produced from an ordinary least squares (OLS) model. Accordingly, one must be very specific in model selection and the inference that can be made from each statistical test.

While many of the issues associated with estimating household water demand can be alleviated with a fixed effects model, doing so necessitates the omission of time invariant factors, which may be useful in predicting and understanding demand. Accordingly, we use two model specifications, consistent with previous work (Kenney 2008; Espey et al. 2003; Schleich and Hillenbrand 2009): a pooled OLS where E\&S households are indicated with a dummy variable and a fixed effects model with interaction dummies for E\&S households.

While the standard OLS model (Model 1) may suffer from endogeneity issues, our coefficient estimates are qualitatively consistent across models (although price elasticities are lower in the FE specification). Both of these points increase confidence in our results. The fixed effects interaction model (Model 2) is used to reduce the possibility of unobserved heterogeneity and the risk of biased estimates. It does not, however, allow for the examination of time invariant information, and thus, does not provide insight into the relationship between many household characteristics and water use that may be of interest. We include the OLS model to provide insight into the relationship between time invariant household characteristics and water demand, 
but a Hausman test suggests fixed effects are required $(\chi=42.1)$. Accordingly, the specific models used in our estimation are consistent with previous literature and described below (Kenney et al. 2008; Espey, et al. 1997; Arbués et al. 2016; Willis et al. 2013; Willis et al. 2011).

Model 1: Pooled OLS with E\&S dummy

$$
y_{i t}=x_{i t} \beta+h_{i} \gamma+d_{i} \rho+\epsilon_{i t}
$$

where $y_{i t}$ is the amount of water consumed by household $i$ in time period $t . x_{i t}$ is a vector of time-varying explanatory variables including price, average daily temperature, and precipitation. $h_{i}$ is a vector of time invariant household characteristics, including age of home, house size (sf), total property turf area (acres), dummy variables for income level (low, middle, high), and the total number of occupants in the home. Each of these variables in vector $x_{i t}$ and $h_{i}$ have been included as controls since previous work has found them to significant influence household water consumption (Ouyang et al., 2013; Arbués at al., 2003; Dalhuisen et al., 2003). The primary interest of this paper is motivation types, which are represented by dummy variable $d_{i}$, which takes a value of 1 if consumer $i$ is identified as E\&S motivated and 0 if a consumer is $\mathrm{C} \& \mathrm{C}$ motivated. $\beta, \gamma$ and $\rho$ are coefficients to be estimated and $\epsilon_{i t}$ is an error term with a mean of zero. The Appendix (A1) contains a list of all variables used in the estimation of both models.

Model 2: OLS fixed effects with interactions

$$
\tilde{y}_{i t}=\tilde{x}_{i t} \beta+d_{i} \tilde{x}_{i t} \gamma+\alpha_{i}+\epsilon_{i t}
$$

where $\tilde{y}_{i t}$ is the demeaned amount of water consumed by household $i$ in time period $t . \tilde{x}_{i t}$ is a demeaned vector of explanatory variables, and $\alpha_{i}$ is a household specific intercept term.

We test for heteroscedasticity in the OLS model with a standard Breusch-Pagan test. For the FE model we use the modified test suggested by Greene (2003) and operationalized by Baum (2001). Heteroscedasticity is present in both models $(\chi=42.1$ and $\chi=4330.3)$. Accordingly, we adjust our standard error estimates in Model 1 with White's correction and use robust standard error estimates clustered at the household level in Model 2. We also test for autocorrelation in both models with a Breusch-Godfrey and the modified Breusch-Godfrey suggested by Woolridge (2010) and find no evidence that such a pattern exists.

\section{Other data sources}

Billing data and survey responses were matched to the county assessor's database to obtain specific physical information about each household. Consistent with previous literature, we include age of home and size of home as explanatory variables. In addition to the assessor's data, we matched households to a parcel-specific LiDAR (Light Detection and Ranging) analysis, which provides a grass area estimate for each household in the sample. Demographic information was collected during the utility-sponsored survey. Lastly, weather observations recorded by CoAgMet stations were matched to specific billing cycles to provide average daily temperature and precipitation estimates corresponding to each bill. 
Due to the wide range of data sources, a substantial portion of the households originally surveyed was dropped to ensure each observation had complete data. Additionally, obvious outliers were omitted from the analysis (a complete explanation of the data cleaning process is provided in the Appendix (A2)). After matching household survey responses across the different datasets, 6,759 observations for 119 distinct surveyed households remain. Although the sample is small, there is no identifiable reason to suggest that missing households are systematically related and would lead to biased sampling. Summary statistics describing households in the sample are reported in Table 1. Use and weather summary statistics are reported in Table 2.

Table 1. Summary Statistics: Household Characteristics

\begin{tabular}{lllll}
\hline (n=119) & Mean & Std. Dev. & Min & Max \\
\cline { 2 - 5 } Single family homes & 0.97 & 0.18 & 0 & 1 \\
\# persons/ household & 2.56 & 1.30 & 1 & 8 \\
Grass area (acres) & 0.011 & 0.006 & 0 & 0.032 \\
House size (sf) & 1566.04 & 476.00 & 780 & 2745 \\
Conservation (Q1) & 6.90 & 1.79 & 0 & 9 \\
Environmental (Q2) & 5.95 & 2.56 & 0 & 9 \\
Social (Q2) & 5.01 & 2.76 & 0 & 9 \\
Cost (Q3) & 6.53 & 2.42 & 0 & 9 \\
Convenience (Q4) & 7.05 & 1.83 & 0 & 9 \\
\hline
\end{tabular}

Table 2. Summary Statistics: Monthly Variables

\begin{tabular}{lllll}
\hline$(\mathrm{n}=6,759)$ & Mean & Std. Dev. & Min & Max \\
\cline { 2 - 5 } Water Use $(\mathrm{gal})$ & 7835.12 & 6884.08 & 600 & 62400 \\
Price/1,000 $(\mathrm{gal})$ & 2.53 & 0.41 & 0.41 & 6.18 \\
Precipitation $(\mathrm{mm})$ & 28.93 & 31.65 & 0.00 & 173.23 \\
Temperature $\left({ }^{\circ} \mathrm{C}\right)$ & 9.72 & 8.85 & -5.77 & 24.61 \\
\hline
\end{tabular}

\section{Results}

This section presents three sets of results. First, we present a qualitative evaluation of our grouping decision into $\mathrm{E} \& \mathrm{~S}$ and $\mathrm{C} \& \mathrm{C}$ customers, then we evaluate and test for differences in household characteristics across these groups. Lastly, we present statistical tests and regression results to evaluate our three main hypotheses.

Our initial investigation into the relatedness of motivations (social, environmental, cost, and convenience) is one of correlations. Table 3 presents a correlation matrix. Using this table, we observe a very strong positive relationship between environmental and social motivation (0.72), both of which are negatively correlated with convenience and relatively uncorrelated with cost. This result suggests that our a priori group division was justified. However, it is worth noting that while social and environmental question responses are strongly related, cost and convenience do not have a similar relationship. Thus, we also use PCA to determine how effective these motivation types are in separating the sample. Figures 1 and 2 present our results. 
Figure 1 displays a clear and strong grouping of E\&S and $\mathrm{C} \& \mathrm{C}$ consumers based on components one and two. Figure 2 suggests the environmental and social motivations are similar in their magnitude and direction of group separation. Convenience is equally important in driving group separation, however cost provides little information ${ }^{1}$. Nevertheless, these results strongly support our group divisions and provide some insight into consumer motivation profiles that can be more rigorously examined in future work.

Table 3. Correlation Matrix of Survey Responses

\begin{tabular}{lccccc}
$(\mathrm{n}=119)$ & \multicolumn{1}{l}{ cost } & convenience \\
& conserve & enviro & social & & \\
conserve & 1.000 & & & & \\
enviro & 0.398 & 1.000 & & & \\
social & 0.300 & 0.720 & 1.000 & & \\
cost & 0.220 & 0.184 & 0.223 & 1.000 & 1.000 \\
convenience & 0.118 & -0.108 & -0.48 & 0.041 & \\
\hline
\end{tabular}

Figure 1.

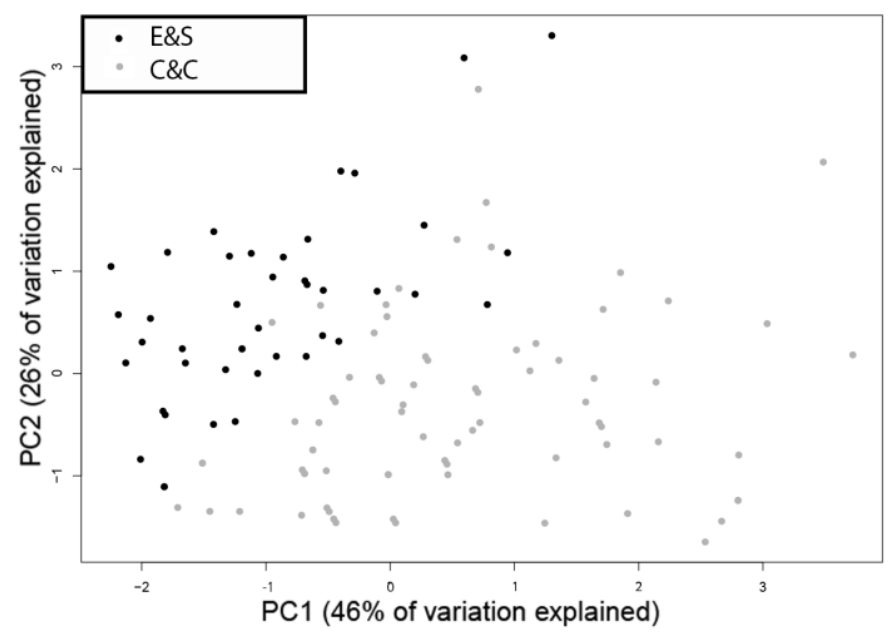

E\&S consumers are identified in black while $\mathrm{C} \& \mathrm{C}$ consumers are gray. The above plots illustrated grouping in the data into PC1-PC2 space.
Figure 2.

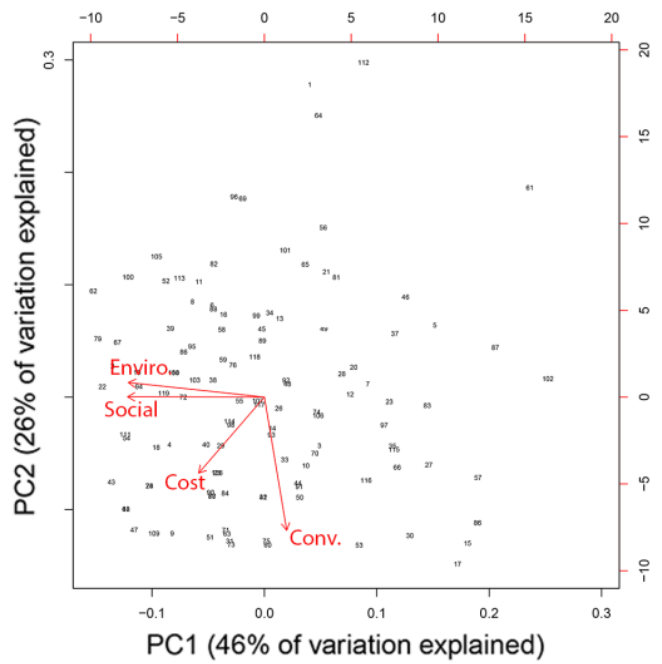

This bi-plot presents the relationship of components 1 and 2 to each motivations variable.

We observe clear divisions in customer motivation types based on the above analysis, but it does not provide insight into differences in observable household characteristics across these groups. Accordingly, Table 4 provides summary statistics of explanatory variables grouped by motivation type and denotes if they are significantly different across groups (as estimated by a t-

\footnotetext{
${ }^{1}$ Because of this result, we provide a number of other group specifications in our Appendix, in which groups were separated by cost and convenience. Results from these regressions are qualitatively similar insofar as E\&S consumers use less overall and do not behave differently from other groups with variations in price and weather.
} 
test or, in the case of binary variables, a chi-squared test). E\&S and C\&C households are significantly different across a number of characteristics, including household size, number of persons per household, and their effort to reduce water consumption as elicited by the survey. Low-income households are more likely to be E\&S motivated, although there is no statistical difference for middle and high income groups. There is also no significant difference in grass area between household types, which is surprising given the environmental cost of turf lawns.

Table 4. Household Characteristics by Consumer type

\begin{tabular}{|c|c|c|c|}
\hline & $\mathrm{C} \& \mathrm{C}$ & $\mathrm{E} \& S$ & \\
\hline Water Use (gal) & $\begin{array}{l}8358.6 \\
(109.0)\end{array}$ & $\begin{array}{l}6899.9 \\
(126.3)\end{array}$ & $* * *$ \\
\hline Grass Area (acres) & $\begin{array}{l}0.011 \\
(0.00068)\end{array}$ & $\begin{array}{l}0.011 \\
(0.0011)\end{array}$ & \\
\hline House size (sf) & $\begin{array}{l}1611 \\
(57.23)\end{array}$ & $\begin{array}{l}1481 \\
(65.25)\end{array}$ & $*$ \\
\hline \# Persons & $\begin{array}{l}2.733 \\
(0.161)\end{array}$ & $\begin{array}{l}2.256 \\
(0.163)\end{array}$ & $* *$ \\
\hline Conservation (0-9) & $\begin{array}{l}6.55 \\
(0.198)\end{array}$ & $\begin{array}{l}7.512 \\
(0.267)\end{array}$ & $* * *$ \\
\hline Low Income (count) & 5 & 9 & $* *$ \\
\hline High Income (count) & 29 & 19 & \\
\hline Obs. & 76 & 43 & \\
\hline
\end{tabular}

Although our coefficient results are highly significant, our OLS model explains only half of total variation, and results must still be interpreted carefully. Additionally, we can identify the effects of environmental attitudes and household characteristics separately, thus reducing the spurious correlation that would likely exist without attitudinal variables. However, we cannot confidently preclude the existence of other underlying unobservable variables driving both explanatory factors and water consumption. Nevertheless, the inclusion of variables traditionally omitted from water demand estimation make some headway on the possible unobserved variable bias and endogeneity concerns in previous studies. Coefficient estimates for Model 1 and Model 2 are presented in Table 4 and are largely consistent with previous findings. As expected, water consumption increases with the number of occupants, income, grass area, and the size of a home. These relationships between household physical characteristics and water use have been well established in the literature. The hypotheses posed at the beginning of this article are intended to investigate similar relationships for household motivations; we return to them now.

Hypothesis 1 states that consumers who are environmentally and socially motivated (E\&S consumers) use less water than consumers who are motivated by personal cost and convenience ( $\mathrm{C} \& \mathrm{C}$ consumers). We performed three tests to evaluate this proposition, the simplest of which is 
a t-test ${ }^{2}$, which yielded a t-statistic of 10.26. Thus, the unconditional mean of water consumption is significantly different across $\mathrm{E} \& \mathrm{~S}$ and $\mathrm{C} \& \mathrm{C}$ consumers. While the unconditional mean is useful, it does not allow us to separate the effect of motivation from underlying characteristics that may be correlated with motivation. To investigate the conditional mean, we examine the results in Table 4 (column 1), where E\&S motivated consumers are represented with a dummy variable. The E\&S dummy variable in Table 4 (column 1) is statistically significant and negative, suggesting that E\&S motivated consumers use significantly less water than those motivated by C\&C conditional on weather and household characteristics. These results allow us to conclude that the E\&S consumers use less water than their C\&C counterparts.

${ }^{2}$ Given the skewness of the distribution of monthly water consumption, data were log transformed to more closely fit a normal distribution. 
Table 5. Model 1 and 2 Regression Results

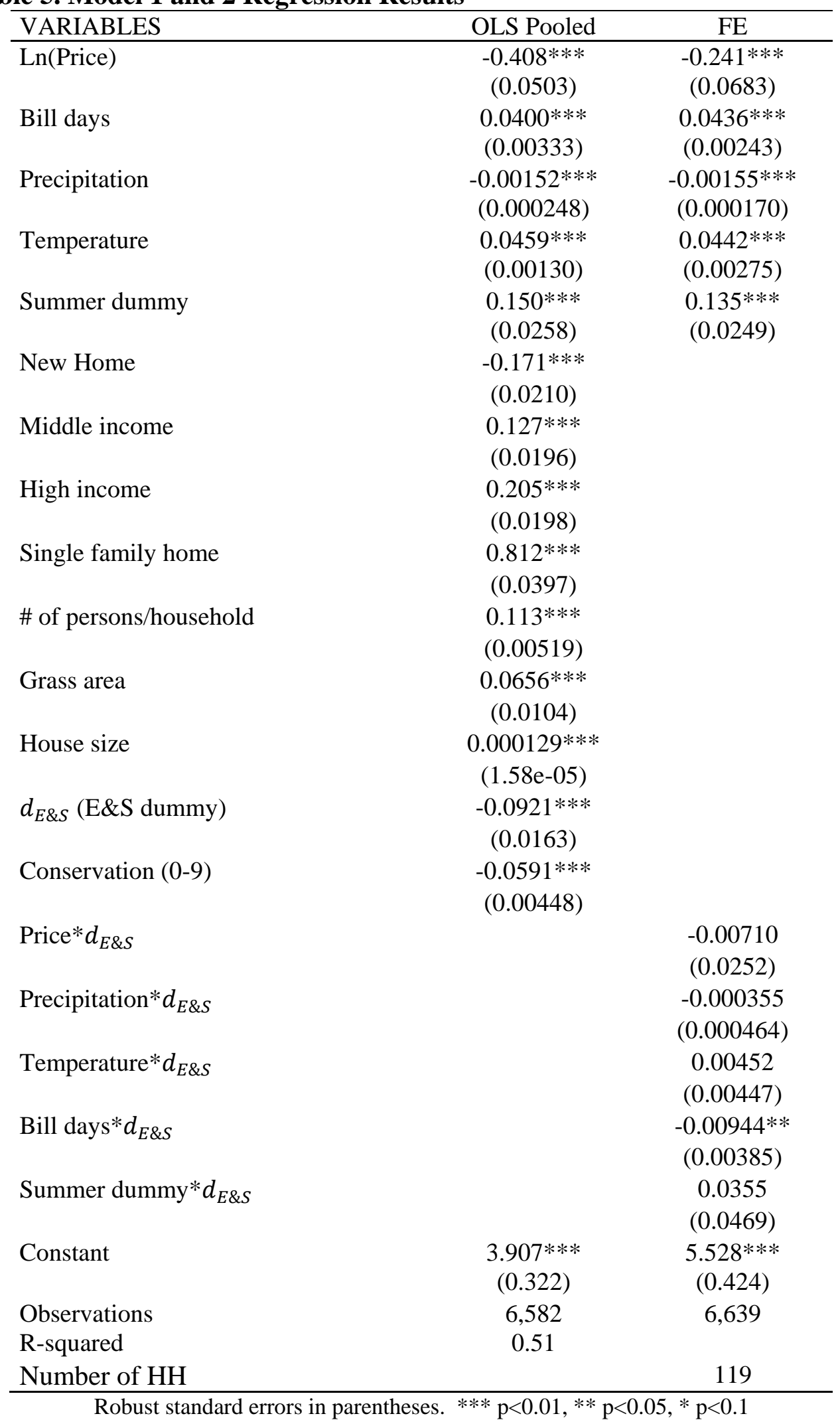


The second hypothesis states that E\&S consumers respond less to changes in price than $\mathrm{C} \& \mathrm{C}$ consumers, presumably because cost savings motivate $C \& C$ customers to reduce more relative to E\&S customers. The most straightforward way to evaluate this hypothesis is evaluating the interaction terms in the FE-interaction model (Table 4, column 2). The price-E\&S interaction term is insignificant, suggesting there is no observable difference across motivation types. Although it is statistically insignificant it is worth noting that the coefficient on the price interaction term is negative, which suggests that customers who claim to be motivated by cost $(\mathrm{C} \& \mathrm{C})$ may be less responsive to price increases than E\&S consumers. While this result is unexpected, it is possible that households that state a strong cost motivation for conservation are implicitly acknowledging their inelastic demand such that cost is a concern precisely because they do not have the ability to respond to price increases with reductions in quantity consumed.

Hypothesis 3 states that $E \& S$ and $C \& C$ consumers will respond equally to changes in precipitation and temperature. This claim is also tested with the FE-interaction model. As expected, both consumer types decrease consumption with precipitation and increase consumption with temperature. Results in Table 4 (column 2) support hypothesis 3 and suggest that there is no statistical difference in how $\mathrm{C} \& \mathrm{C}$ and $\mathrm{E} \& \mathrm{~S}$ consumers respond to precipitation and temperature.

\section{Discussion}

Our overall results suggest that the underlying motivations of residential water consumers affect consumption but do not affect how consumers respond to exogenous weather and price shocks. Consumers motivated by environmental preference use less, which suggests that they conserve consistent with their attitudes. However, their response to external shocks like weather and price are not statistically different from other consumers.

While our results suggest that environmentally and socially motivated households use less water than those homes concerned with cost and convenience, more work is necessary to further elucidate this relationship. If environmental motivation is the true cause of conservation, significant implications exist for municipal-sponsored education and conservation programs. Moreover, because there is no difference in how consumers respond to price and weather shocks, water providers should not tailor education campaigns to the stated motivations of their customers. For example, if customers claim to be primarily motivated by cost, one might assume that increasing price would be an effective way to induce conservation. However, there is no differential response to price across customer types such that tailoring campaigns in this way is unlikely to increase conservation relative to the case where this policy is more widely promoted.

Conservation education is a common tool used by water suppliers, but its effectiveness is poorly understood. A key question in determining the effectiveness of conservation programs is the specific mechanism by which they work. For example, some programs may provide specific knowledge that allows individuals to conserve through new behaviors of which they may have been previously unaware. Other programs may foster pro-environmental attitudes that increase the utility consumers get from conserving. Our initial results indicate that environmental 
attitudes - at least stated ones - are associated with lower water consumption, which may suggest that education and conservation programs that foster social and pro-environmental attitudes may be a practical strategy to induce conservation.

Future work on this topic should help identify the specific means by which E\&S consumers use less water than their $\mathrm{C} \& \mathrm{C}$ counterparts. Moreover, better understanding around the immediate and long-term behavioral effects of educational and conservation campaigns to engender social and environmental attitudes has significant implications for water suppliers. 


\section{ACKNOWLEDGEMENTS}

This work was funded by NSF Sustainability Research Network (SRN) Cooperative Agreement 1444758

Funding was also provided by a National Science Foundation IGERT Grant No. DGE0966346: I-WATER: Integrated Water, Atmosphere, Ecosystem Education and Research Program at Colorado State University

\section{REFERENCES}

Agras, W. Stewart, Rolf .G Jacob, and Melissa Lebedeck. 1980. "The California Drought: A Quasi-experimental Analysis of Social Policy.” Journal of Applied Behavior Analysis 13 (4). 561-70.

Arbués, Fernando, Miguel Ángel Bolsa, and Inmaculada Villanúa. 2016. "Which Factors Determine Water Saving Behaviour? Evidence from Spanish Households." Urban Water Journal 13 (5). 511-20.

Arbués, Fernando, Marıa Ángeles Garcıa-Valiñas, and Roberto Martınez-Espiñeira. 2003. "Estimation of Residential Water Demand: A State-of-the-Art Review." Journal of SocioEconomics 32 (1). 81-102.

Ballantyne, Roy, and Jan Packer. 2005. "Promoting Environmentally Sustainable Attitudes and Behaviour through Free-choice Learning Experiences: What Is the State of the Game?" Environmental Education Research 11 (3). 281-95.

Baum, C.F. and Wiggins, V., 1999. BPAGAN: Stata module to perform Breusch-Pagan test for heteroskedasticity. Statistical Software Components.

Billings, R. Bruce, and Mark Day. 1989. "Demand Management Factors in Residential Water Use: The Southern Arizona Experience.” Journal of the American Water Works Association 81 (3). 58-64.

Cialdini, Robert B., Raymond R. Reno, and Carl A. Kallgren. 1990. "A Focus Theory of Normative Conduct: Recycling the Concept of Norms to Reduce Littering in Public Places." Journal of Personality and Social Psychology 58 (6). 1015-1026.

Corral-Verdugo, Víctor, Robert B. Bechtel, and Blanca Fraijo-Sing. 2003. "Environmental Beliefs and Water Conservation: An Empirical Study." Journal of Environmental Psychology 23 (3). 247-57.

Corral-Verdugo, Víctor, and Martha Frías-Armenta. 2006. "Personal Normative Beliefs, Antisocial Behavior, and Residential Water Conservation." Environment and Behavior 38 (3): 406-21.

Dalhuisen, Jasper M., Raymond J.G.M. Florax, Henri L.F. De Groot, and Peter Nijkamp. 2003. "Price and Income Elasticities of Residential Water Demand: A Meta-analysis." Land Economics 79, 2. 292-308.

Diekmann, Andreas, and Peter Preisendörfer. 1998. "Environmental Behavior Discrepancies between Aspirations and Reality." Rationality and Society 10 (1). 79-102.

Espey, Molly, James Espey, and Douglass W. Shaw. 1997. "Price Elasticity of Residential Demand for Water: A Meta-Analysis.” Water Resources Research 33 (6). 1369-74.

Farmer, James, Doug Knapp, and Gregory M Benton. 2007. “An Elementary School 
Environmental Education Field Trip: Long-Term Effects on Ecological and Environmental Knowledge and Attitude Development." Journal of Environmental Education 38 (3). 3342.

Gleick, P. H., 2000. “A Look at Twenty-first Century Water Resources Development. Water International, 25(1). 127-138.

Gilg, Andrew, and Stewart Barr. 2006. "Behavioural Attitudes towards Water Saving? Evidence from a Study of Environmental Actions." Ecological Economics 57 (3). 400-414.

Greene, William H. 2003. Econometric analysis. Pearson Education India.

Gregory, Gary and Michael Di Leo. 2003. "Repeated Behavior and Environmental Psychology: The Role of Personal Involvement and Habit Formation in Explaining Water Consumption.” Journal of Applied Social Psychology 33 (6): 1261-96.

Hungerford, Harold R, and Trudi L Volk. 1990. "Changing Learner Behavior through Environmental Education.” Journal of Environmental Education 21 (3). 8-21.

Kenney, Douglas S, Christopher Goemans, Roberta Klein, Jessica Lowrey, and Kevin Reidy. 2008. "Residential Water Demand Management: Lessons from Aurora, Colorado." Journal of the American Water Resources Association 44 (1). 192-207.

Kollmuss, Anja, and Julian Agyeman. 2002. "Mind the Gap: Why Do People Act Environmentally and What Are the Barriers to Pro-environmental Behavior?" Environmental Education Research 8 (3). 239-60.

Michelsen, An M, J Thomas McGuckin, and Donna Stumpf. 1999. "Nonprice Water Conservation Programs As A Demand Management Tool." Journal of the American Water Resources Association 35 (3). 593-602

Millock, Katrin, and Céline Nauges. 2010. "Household Adoption of Water-Efficient Equipment: The Role of Socio-Economic Factors, Environmental Attitudes and Policy." Environmental and Resource Economics 46 (4). 539-65.

Nieswiadomy, Michael L. 1992. "Estimating Urban Residential Water Demand: Effects of Price Structure, Conservation, and Education." Water Resources Research 28 (3). 609-15.

Olmstead, Sheila M, W Michael Hanemann, and Robert N Stavins. 2007. "Water Demand under Alternative Price Structures." Journal of Environmental Economics and Management 54 (2). 181-98.

Olmstead, Sheila M, and Robert N Stavins. 2009. "Comparing Price and Nonprice Approaches to Urban Water Conservation." Water Resources Research 45 (4).

Ouyang, Yun, Elizabeth A Wentz, Benjamin L Ruddell, and Sharon L Harlan. 2014. “A Multi - Scale Analysis of Single - Family Residential Water Use in the Phoenix Metropolitan Area. Journal of the American Water Resources Association 50 (2). 448-67.

Poortinga, Wouter, Linda Steg, and Charles Vlek. 2004. "Values, Environmental Concern, and Environmental Behavior a Study into Household Energy Use." Environment and Behavior 36 (1). 70-93.

Randolph, Bill, and Patrick Troy. 2008. "Attitudes to Conservation and Water Consumption." Environmental Science \& Policy 11 (5). 441-55.

Schleich, Joachim, and Thomas Hillenbrand. 2009. "Determinants of Residential Water Demand in Germany." Ecological Economics 68 (6). 1756-69.

Taylor, Shirley, and Peter Todd. 1997. "Understanding the Determinants of Consumer Composting behavior.” Journal of Applied Social Psychology 27 (7). 602-28.

Trumbo, Craig, and Garrett J. O'Keefe. 2001. "Intention to Conserve Water: Environmental Values, Planned Behavior, and Information Effects. A Comparison of Three Communities 
Sharing a Watershed.” Society \&Natural Resources 14 (10). 889-99.

Tuan, Yi-Fu. 1968. "Discrepancies between Environmental Attitude and Behaviour: Examples from Europe and China." The Canadian Geographer/Le Géographe Canadien 12 (3). 17691.

Willis, Rachelle M, Rodney A Stewart, Damien P Giurco, Mohammad Reza Talebpour, and Alireza Mousavinejad. 2013. "End Use Water Consumption in Households: Impact of Socio-Demographic Factors and Efficient Devices." Journal of Cleaner Production 60. 107-15.

Willis, Rachelle M, Rodney A Stewart, Kriengsak Panuwatwanich, Philip R Williams, and Anna L Hollingsworth. 2011. "Quantifying the Influence of Environmental and Water Conservation Attitudes on Household End Use Water Consumption.” Journal of Environmental Management 92 (8). 1996-2009.

Wooldridge, Jeffrey M. 2010. Econometric analysis of cross section and panel data. MIT press. Cambridge MA.

Worthington, Andrew C., and Mark Hoffman. 2008. "An Empirical Survey of Residential Water Demand Modelling." Journal of Economic Surveys 22 (5). 842-71.

Zsóka, Ágnes, Zsuzsanna Marjainé Szerényi, Anna Széchy, and Tamás Kocsis. 2013. “Greening due to Environmental Education? Environmental Knowledge, Attitudes, Consumer Behavior and Everyday pro-Environmental Activities of Hungarian High School and University Students." Journal of Cleaner Production 48. 126-38. 


\section{APPENDIX}

\section{A1. Variables Used in the Analysis}

Table A1. Description of Variables

$\mathrm{Ln}$ (Consumption) (gal) Log transformed number of gallons used in billing period

Price

Bill days

Precipitation

Temperature

Summer dummy

Middle income

High income

Single family home

\# of persons

$\mathrm{E} \& \mathrm{~S}$ (dummy)

Ln(Grass area)

House size (sf)

Environmental (0-9)

Social (0-9)

Cost (0-9)

Convenience (0-9)

Conservation (0-9)
Average variable price of last month's bill

Number of days for which consumer was billed

Cumulative precipitation of billing period $(\mathrm{mm})$

Daily average temperature of billing period, calculated as:

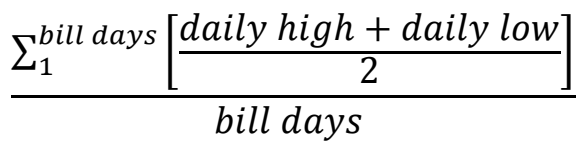

A dummy variables that takes a value of 1 for June, July and August, and 0 otherwise.

A dummy variable that takes the value of 1 if survey respondents claimed an income between $\$ 35,000$ and $\$ 74,999$ and 0 otherwise

A dummy variable that takes the value of 1 if survey respondents claimed an income above $\$ 74,999$ and 0 otherwise

A dummy variable that takes the value of 1 if survey respondents lives in a single family home and 0 otherwise

Number of persons in the household as recorded by the survey

A dummy variable that takes the value of 1 if survey respondents answers were such that Q2+Q3 > Q4+Q5 and 0 otherwise

Log transformed acres of turf, estimated by 2012 LiDar

Square footage of home, defined by the Larimer Assessor's office

The Likert Scale Response to survey question 2

The Likert Scale Response to survey question 3

The Likert Scale Response to survey question 4

The Likert Scale Response to survey question 5

The Likert Scale Response to survey question 1 


\section{A2. Data Cleaning}

Given the necessity to merge datasets from various sources, mistakes present in the billing data, and oddities that may not represent normal water use, the data used in our regression analyses has been cleaned according to a number of rules. Specifically, observations were dropped if:

- Consumption $>60,000$ gallons per month

- Consumption $<300$ per month

- $\operatorname{Bill}(\$)<0$

- Surveys were not complete

- $\quad$ [Parcel area (LiDar) - Parcel Area (Assessor)] $\mid>200$ sqft

- Bill days $<26$ or Bill days $>36$

- Customer account number existed for $>2$ properties

- Observation could not be merged across all datasets

- Average Variable Price < 0

- Customer code changes for a given tap (suggests a change in occupancy)

\section{A3. Additional Analysis and Grouping}

To test for robustness in our results, a number of additional model specifications are included in Table A3. When survey questions are included in the OLS model as continuous variables, the results are qualitatively similar to those reported in the body of the paper. Note that increases in the scores of environmental motivation are associated with the largest decrease in water use, which is consistent with our finding that $\mathrm{E} \& \mathrm{~S}$ consumers use less than $\mathrm{C} \& \mathrm{C}$ consumers. It is worth noting that under this formulation, environmental motivations are the only ones that significantly decrease consumption, suggesting that the motivation for lower water use seen in E\&S consumers is largely environmental.

Table A4 presents the regression results of customer motivation types similar to that presented in the main paper, except groups were created only with the environmental and cost questions. Note that the same qualitative results persist, suggesting that environmentally motivated households consume less and that there is no significant difference in how each household type responds to changes in price and weather. 
Table A3. Pooled OLS Regression with Continuous Survey Variables

\begin{tabular}{|c|c|}
\hline VARIABLES & OLS Pooled \\
\hline \multirow[t]{2}{*}{ Ln(Price) } & $-0.403 * * *$ \\
\hline & $(0.0497)$ \\
\hline \multirow[t]{2}{*}{ Bill days } & $0.0403 * * *$ \\
\hline & $(0.00330)$ \\
\hline \multirow[t]{2}{*}{ Precipitation } & $-0.00152 * * *$ \\
\hline & $(0.000246)$ \\
\hline \multirow[t]{2}{*}{ Temperature } & $0.0459 * * *$ \\
\hline & $(0.00129)$ \\
\hline \multirow[t]{2}{*}{ Summer dummy } & $0.149 * * *$ \\
\hline & $(0.0256)$ \\
\hline \multirow[t]{2}{*}{ New home } & $-0.176 * * *$ \\
\hline & $(0.0214)$ \\
\hline \multirow[t]{2}{*}{ Middle income } & $0.133 * * *$ \\
\hline & $(0.0198)$ \\
\hline \multirow[t]{2}{*}{ High income } & $0.223 * * *$ \\
\hline & $(0.0202)$ \\
\hline \multirow[t]{2}{*}{ Single Family home } & $0.796 * * *$ \\
\hline & $(0.0417)$ \\
\hline \multirow[t]{2}{*}{ \# of persons/household } & $0.109 * * *$ \\
\hline & $(0.00510)$ \\
\hline \multirow[t]{2}{*}{ Ln(Grass Area) } & $0.0687 * * *$ \\
\hline & $(0.0103)$ \\
\hline \multirow[t]{2}{*}{ House size (sf) } & $0.000111 * * *$ \\
\hline & $(1.63 \mathrm{e}-05)$ \\
\hline \multirow[t]{2}{*}{ Environmental (0-9) } & $-0.0254 * * *$ \\
\hline & $(0.00419)$ \\
\hline \multirow[t]{2}{*}{ Social (0-9) } & $0.0275 * * *$ \\
\hline & $(0.00352)$ \\
\hline \multirow[t]{2}{*}{ Cost (0-9) } & $0.00822 * * *$ \\
\hline & $(0.00291)$ \\
\hline \multirow[t]{2}{*}{ Convenience (0-9) } & $0.0264 * * *$ \\
\hline & $(0.00399)$ \\
\hline \multirow[t]{2}{*}{ Conservation (0-9) } & $-0.0700 * * *$ \\
\hline & $(0.00471)$ \\
\hline \multirow[t]{2}{*}{ Constant } & $3.807 * * *$ \\
\hline & $(0.319)$ \\
\hline Observations & 6,582 \\
\hline R-squared & 0.495 \\
\hline
\end{tabular}


Table A4. Regression Output only Considering Environmental and Cost Motives

VARIABLES

OLS Pooled with Dummy

(2)

\section{Ln(Price)}

Bill days

Precipitation

Temperature

Summer dummy

New home

Middle income

High income

Single Family home

\# of persons/household

Ln(Grass Area)

House size (sf)

$d_{E}$ (dummy)

Price* $d_{E}$

Precipitation $* d_{E}$

Temperature $* d_{E}$

Bill days $* d_{E}$

Summer dummy* $d_{E}$

Constant

Observations

R-squared

Number of households

$-0.362 * * *$

(0.0537)

$0.0398 * * *$

(0.00364)

$-0.00153^{* * * *}$

$(0.000273)$

$0.0450 * * *$

(0.00143)

$0.141 * * *$

(0.0282)

$-0.289 * * *$

(0.0356)

$-0.0113$

(0.0224)

$0.0933 * * *$

(0.0221)

$1.056^{* * *}$

(0.0411)

$0.130 * * *$

(0.00545)

$0.0687 * * *$

$(0.0103)$

$0.000152 * * *$

(1.81e-05)

$-0.105^{* * *}$

(0.0157)

FE Interactions

$-0.170 * * *$

(0.0519)

$0.0424 * * *$

$(0.00353)$

$-0.00151^{* * * *}$

$(0.000210)$

$0.0444 * * *$

(0.00133)

$0.123 * * *$

(0.0254)

$$
\begin{gathered}
-0.108 \\
(0.0765) \\
-0.000581 \\
(0.000537) \\
0.00169 \\
(0.00194) \\
-0.00564 \\
(0.00542) \\
0.0552 \\
(0.0443) \\
5.687 * * * \\
(0.242)
\end{gathered}
$$

$3.207 * * *$

$(0.336)$

5,687

0.537

102

Robust standard errors in parentheses

$$
* * * \mathrm{p}<0.01, * * \mathrm{p}<0.05 \text {, * } \mathrm{p}<0.1
$$

